\title{
Leveraging emotion-behavior pathways to support environmental behavior change
}

\author{
Katie Williamson ${ }^{1 *}$ and Erik Thulin ${ }^{1}$ \\ ${ }^{1}$ Center for Behavior \& the Environment, Rare
}

\begin{abstract}
:
Many global environmental threats are driven by human behavior and require behavioral solutions. Researchers in the environmental field have recently begun seeing the behavioral sciences as core to changing behavior for conservation; yet leveraging human emotions remains an underused tool for behavior change compared to others like social norms. Humans experience a range of emotions that each cause distinct patterns of behavior depending on unique contexts; this presents an opportunity to leverage emotions to support behavior change goals. The existing literature offers minimal guidance about which specific emotions to use in which contexts and how those emotions might lead to certain behaviors. In the environmental field specifically, there have been mixed results on using emotions, resulting from an incomplete understanding of the causal relationship between particular emotions, contexts, and environmental behaviors. We propose that adopting a functionalist approach, which describes emotions as functional states designed to produce particular outcomes in specific contexts, will help to unlock emotions as a tool for conservation. To demonstrate this approach, we identify fear, joy, hope, anger, pride, interest, and the prospect of shame as particularly relevant for environmental behavior change. Based on an understanding of each emotion's function, we developed an emotion-behavior pathway that describes the expected outcome of using an emotion in a particular context. Applying these emotional-behavior pathways can allow both researchers and practitioners to advance the science of shifting environmental behavior through emotion.
\end{abstract}

Key words: Decision-making; emotion; environment; behavior change; affect

*Corresponding author: kwilliamson@rare.org

Acknowledgements: We thank Kevin Green, Erez Yoeli, Kenneth Wallen, Philipe Bujold, Kate Mannle, Claudia Quintanilla, Natalie Rodríguez Dowdell, Divina Lade, and members of Rare's Center for Behavior \& the Environment for their feedback and contributions to this manuscript.

Version 08/26/2021 


\section{INTRODUCTION}

The pace and scale of climate change, biodiversity loss, and natural resource depletion threaten to cross planetary boundaries that support life on Earth (Steffen et al. 2015). There is a growing recognition in the conservation field that not only is human behavior a root cause of environmental change but also that behavior change is critical for achieving environmental outcomes (Cinner 2018, Nielsen et al. 2021, Balmford et al. 2021). While some researchers have explored applying key behavioral science tools to address these challenges, such as social norms and choice architecture, less work has been done to understand emotions as a powerful tool to drive behavior change for conservation.

While there are many ways to conceptualize emotions, focusing on the function that emotions serve provides a way to understand the relationship between emotions and behavior change. A functional approach describes emotions as functional states that have emerged over time based on patterns of certain situations that produced certain outcomes relevant to our fitness as a species (Fessler and Haley 2003, Frijda 2007, Nesse and Ellsworth 2009, Lerner et al. 2015). A functional understanding of emotions further emphasizes how our emotions cause us to act, construct meaning, and respond adaptively to everyday life events and longer-term goals (Lazarus 2001, Frijda 2004, Carver et al. 2014). While some researchers treat emotions as purely 'irrational' decision-making patterns, the evolutionary emergence of emotions suggest that they exist to help us navigate the complexity of our environment and ultimately survive (Peters et al. 2006, Williams and DeSteno 2014, Lerner et al. 2015, Adolphs and Andler 2018). Because a functional understanding forecasts behavioral consequences for a given emotion, it presents an opportunity for us to leverage them to support behavior change goals.

The academic literature includes a wealth of evidence for the functional underpinnings of various emotions. However, this evidence is rarely translated for, or used by, behavior change researchers and practitioners linking certain emotions to behaviors. In the conservation field specifically, there have been mixed results on using emotions, resulting from an incomplete understanding of the causal relationship between particular emotions, contexts, and environmental behaviors (Chapman et al. 2017, Nabi et al. 2018, Kidd et al. 2019, McAfee and Connell 2019). A theory-based functional approach would likely be far more fruitful, directing researchers and behavioral intervention designers to emotions most likely to lead to behavior change. Such a shift in thinking about emotions requires the translation of function-based emotions literature into actionable guidance. In this article, we demonstrate how this can be done to support researchers and practitioners, and advocate for further translation of this literature on other emotions and contexts.

\section{EMOTION-BEHAVIOR PATHWAYS FOR CONSERVATION}

To demonstrate the utility of conceptualizing emotions and their behavioral consequences, we analyze fear, hope, the prospect of shame, pride, joy, anger, and interest. For each emotion, we describe an emotion-behavior pathway that demonstrates the expected outcome of using an emotion in a particular context. These pathways can serve as actionable starting points for testing and implementing different emotion-based interventions to increase our impact on behavior change for conservation. 


\begin{tabular}{|c|c|}
\hline Emotion & Emotion-behavior pathway \\
\hline Fear & $\begin{array}{l}\text { Use to motivate people to avoid risks when they experience uncertainty } \\
\text { or an immediate threat }\end{array}$ \\
\hline Hope & $\begin{array}{l}\text { Use to motivate people to start a behavior when they can achieve a } \\
\text { desired outcome while facing a threat. }\end{array}$ \\
\hline Prospect of shame & $\begin{array}{l}\text { Use to motivate people to avoid a socially-undesirable action when } \\
\text { others might find out. }\end{array}$ \\
\hline Pride & $\begin{array}{l}\text { Use to motivate people to show others what they have done when they } \\
\text { have engaged in reputation-enhancing behavior }\end{array}$ \\
\hline Joy & $\begin{array}{l}\text { Use joy to motivate people to continue a behavior when they have } \\
\text { achieved a goal or gained resources. }\end{array}$ \\
\hline Anger & $\begin{array}{l}\text { Use to motivate people to confront others when they experience or } \\
\text { witness something that goes against their values. }\end{array}$ \\
\hline Interest & $\begin{array}{l}\text { Use to motivate people to seek information when something is novel } \\
\text { and complex }\end{array}$ \\
\hline
\end{tabular}

Table 1. Emotion-behavior pathways in context for seven emotions relevant for environmental behavior change.

\section{Fear: Use to motivate people to avoid risks when they experience uncertainty or an immediate threat}

Fear's main function as an emotion is to help people avoid harm and risks in the near or immediate future (Condon et al. 2014, Nabi et al. 2018). Various studies have found that eliciting fear leads to less risky decision-making and more pessimistic views of situations, increasing the perception of risk (Hargie 2010, Xie et al. 2011). Researchers examining the use of fear on environmental challenges have observed that fear works best for short-term concerns when there are identifiable and immediate threats, such as imminent resource scarcity (Ohman 1993, O'Neill and Nicholson-Cole 2009, Murphy and Murphy 2012, Smith and Leiserowitz 2014). For fear to be most effective, people need to believe that the threat to them is severe, they are vulnerable to this threat, and that they can take action to mitigate that threat (O’Neill and Nicholson-Cole 2009, Hargie 2010, Nabi et al. 2018, Westoby and McNamara 2019). Fear appeals that do not follow these guidelines may cause people to distance themselves from the problem, feel helpless, or disengage altogether (O'Neill and Nicholson-Cole 2009, Smith and Leiserowitz 2014, Weinstein et al. 2015, Nabi et al. 2018). As a result, fear must be used in specific contexts that focus on reducing harm in the near term.

\section{Hope: Use to motivate people to start a behavior when they can achieve a desired outcome while facing a threat.}

Hope functions by motivating people to try something when facing a challenge that they feel they can overcome (Lazarus 1993, 2001, Chadwick 2015). It is an emotion that encourages people to take action and persevere due to its future and goal-oriented nature (Snyder et al. 2002, Chadwick 2015). Hope further works through a perception that there is self or collective efficacy to achieve a future desired state. This results in hope leading to support for social and environmental change (Ojala 2012, Greenaway et al. 2016) and goal motivation (Prestin 2013). Studies suggest that hope is most effective when there is both a realistic understanding of current threats and a genuine belief that those threats could be mitigated; otherwise, presenting hopeful messages can lead people to 
underestimate threats and become complacent in taking action (Swaisgood and Sheppard 2010, Hobbs 2013, Hornsey and Fielding 2016, Nabi et al. 2018). Moreover, people need to believe that they are part of the solution for overcoming threats and have the self-efficacy to do so. Hope encourages people to take action because they think they can and should do something about the threat, not because they think others will take action to reduce the threat.

\section{Prospect of shame: Use to motivate people to avoid a socially undesirable action when others might find out.}

The prospect of shame functions as a motivation for avoiding the negative social judgment for engaging in socially undesirable behavior (Fessler and Haley 2003). This is because the experience of shame itself is highly aversive, making shame an internal subjective penalty for violating a norm (Smith et al. 2002). When an actor is considering whether to engage in a counter-normative behavior, the aversive prospect of experiencing shame reduces the actor's interest in engaging in it (Elster 1998). This results in the actor preserving a positive social standing and avoiding negative social sanctioning. Beliefs about what actions are shameful closely track how negatively valued someone would feel if others found out they engaged in the action (Sznycer et al. 2016). This pattern holds across cultures, from hunter-gathers to large-scale societies (Sznycer et al. 2018). Experiments find that it is precisely this devaluation from others, rather than the wrongdoing itself, which evokes shame; shame avoidance is calibrated to avoid social judgment rather than wrongdoing (Robertson et al. 2018). Behavioral interventions can motivate people to avoid socially undesirable behavior by evoking the prospect of shame by making the anti-social act more observable, a strategy found effective in other pro-social behavior change domains (Panagopoulos 2010).

\section{Pride: Use to motivate people to show others what they have done when they have engaged in reputation-enhancing behavior.}

Pride functions by getting people to engage in and demonstrate to others that they have performed a socially-valued or prestigious act (Fessler and Haley 2003, Tracy et al. 2010, Horberg et al. 2011, Weidman et al. 2016). People will spend time and energy on something to boost their social status and prestige among others to signal that they are doing behaviors deemed important by relevant social groups. Importantly, pride can motivate actions that are socially valued, even if the actor is not consciously calculating how others will perceive it. This emotion has helped to boost pro-social behavior such as voting among high-propensity voters (Panagopoulos 2010) and environmental behavior such as choosing green products or protecting species of flora and fauna (Butler et al. 2013, Bissing-Olson et al. 2016, Schneider et al. 2017). Pride, especially in social contexts, allows people to affirm their shared values and beliefs, while also displaying their competence in doing socially-valued behaviors.

\section{Joy: Use joy to motivate people to continue a behavior when they have achieved a goal or gained resources.}

Joy, or happiness, has a wide range of functions, yet one of its most notable outcomes is to increase positive feelings, energy, or sense of self so that people continue to work to achieve their goals (Lazarus 1993, Fredrickson 1998, Campos and Keltner 2014, Carver et al. 2014). Joy is a relatively short-lived emotion and therefore it can help direct our attention to certain priorities, such as 
something we have just achieved or done well. Joy allows people to feel the benefits of achievement as they work towards their goals, not just when they complete them, which motivates people to continue what they are doing (Carver et al. 2014). Sharing or experiencing joy also helps people to maintain their positive feelings and leads them to receive reinforcement from others about continuing the positive behavior (Lambert et al. 2013, Carver et al. 2014, Clark and Monin 2014). Joy can therefore be leveraged to help people to build knowledge, skills, and resources over time as they find ongoing pleasure and satisfaction in these activities.

\section{Anger: Use to motivate people to confront others when they experience or witness something that goes against their values.}

Anger functions as a motivation for negative sanctioning of norm-violating behavior (van Doorn et al. 2014). This serves two purposes. First, it allows the individual to credibly signal that they will not tolerate being exploited in the future (Guala 2012). Second, anger-motivated sanctioning stabilizes a norm within a community by both broadcasting what is acceptable in this social context (Barclay 2006, Kurzban et al. 2007, Cushman 2013, Jordan et al. 2016), as well as shifting incentives to create a cooperative equilibrium (Boyd and Richerson 1992, Sigmund et al. 2010, Chudek and Henrich 2011).

Across cultures, anger is recognized as an expression of a perceived norm violation. This emotional response signals the belief that someone else is responsible for an unfair outcome, broadcasting the relevant social norm for a given context (van Kleef et al. 2016). Experiments show that experiencing anger causes individuals to punish perpetrators to restore fair outcomes, both when they (Drouvelis and Grosskopf 2016) or others (Fehr and Fischbacher 2004, Nelissen and Zeelenberg 2009, Jordan et al. 2016) are wronged. Consistent with this account, knowing someone is prone to anger leads those around them to be more cooperative with them in the future in environmental contexts (Bloodhart and Swim 2013) and beyond (Hirshleifer 1987, Frank 1988, van Dijk et al. 2008). Anger can, therefore, be leveraged to maintain social norms without top-down enforcement.

\section{Interest: Use to motivate people to seek information when something is novel and complex}

Interest is an emotion that causes people to pay attention to something and facilitates learning and exploration. People are drawn to new or complex things and ideas but also want to understand them; when both of these conditions are met, people feel intrigued instead of confused or overwhelmed (Silvia 2008). Interest causes people to approach what they find interesting, whether they are people, places, things, or experiences, and helps to increase current knowledge (Fredrickson 1998, Silvia 2008). Researchers suspect that interest may help generate new ideas during problemsolving, focusing attention on important tasks, and helping people build a wide range of skills over their lifetimes (Silvia 2008, Campos and Keltner 2014). This emotion has further been shown to help increase engagement on topics such as national policies for climate change as well as perceived risks and hazards (Sjöberg and Sjöberg 2007, Smith and Leiserowitz 2014). As a result, the ability to generate and maintain interest can encourage people to explore concepts they had not considered before.

\section{CONCLUSION}


Behavior change is vital for achieving conservation outcomes. The deliberate application of human emotions provides a relatively untapped source of potential in driving this change. Knowing how to use specific emotions in specific contexts allows for the design of more effective campaigns to realize conservation goals. The functionalist perspective outlined here allows that advice to move beyond general, broad strokes into specific, actionable, context-specific guidance for leveraging emotions.

There are several future directions for continuing to learn about emotions for conservation behavior change. To build more reliable emotion-behavior pathways, target emotions require experimental field testing in a greater set of environmental and social contexts. It is also worth exploring how emotion-behavior pathways may replicate across cultures and geographies. For example, emotions like shame have a robust evidence base to show it exists in many cultures (Sznycer et al. 2018); yet for other emotion-behavior pathways, similar evidence has yet to be demonstrated. Additionally, the expression, social norms, and display rules of each emotion vary in geographic contexts and cultures (van Kleef et al. 2016). We recommend using caution and developing a deep understanding of the behavioral context before testing out the use of any emotion. Finally, as our understanding of emotions and behavior further develops, this creates the opportunity for greater research into how different emotions may interact together to yield patterns of behavior distinct from that expected from any single emotion.

The emotion-behavior pathways demonstrated here are far from exhaustive and instead intended to demonstrate how a deeper functional understanding of each emotion can be leveraged into more effective conservation behavior change programs. This means that perhaps the most important future direction is for researchers at the intersection of behavior and the environment to continue to test and grow the set of emotions identified here to provide a more complete taxonomical account of the emotion-behavior pathways relevant for environmental behavior. Applying emotions will not only support conservation researchers but also practitioners in developing and testing more efficient and effective environmental behavior change programs. 


\section{LITERATURE CITED}

Adolphs, R., and D. Andler. 2018. Investigating emotions as functional states distinct from feelings. Emotion Review 10(3):191-201.

Balmford, A., R. B. Bradbury, J. M. Bauer, S. Broad, G. Burgess, M. Burgman, H. Byerly, S. Clayton, D. Espelosin, P. J. Ferraro, B. Fisher, E. E. Garnett, J. P. G. Jones, T. M. Marteau, M. Otieno, S. Polasky, T. H. Ricketts, C. Sandbrook, K. Sullivan-Wiley, R. Trevelyan, S. van der Linden, D. Veríssimo, and K. S. Nielsen. 2021. Making more effective use of human behavioural science in conservation interventions. Biological Conservation 261:109256.

Barclay, P. 2006. Reputational benefits for altruistic punishment. Evolution and Human Behavior 27(5):325-344.

Bissing-Olson, M. J., K. S. Fielding, and A. Iyer. 2016. Experiences of pride, not guilt, predict proenvironmental behavior when pro-environmental descriptive norms are more positive. Journal of Environmental Psychology 45:145-153.

Bloodhart, B., and J. Swim. 2013. Admonishment and praise: interpersonal mechanisms for promoting pro-environmental behavior. Ecopsychology 5.

Boyd, R., and P. J. Richerson. 1992. Punishment allows the evolution of cooperation (or anything else) in sizable groups. Ethology and Sociobiology 13(3):171-195.

Butler, P., K. Green, and D. Galvin. 2013. The Principles of Pride: The science behind the mascots. Rare.

Campos, B., and D. Keltner. 2014. Shared and differentiating features of the positive emotion domain. Positive emotion: integrating the light sides and the dark sides. Oxford University Press.

Carver, C. S., M. F. Scheier, and S. L. Johnson. 2014. Origins and functions of positive affect: A goal regulation perspective. Pages 34-51 Positive emotion: integrating the light sides and dark sides. Oxford University Press, New York, NY, US.

Chadwick, A. E. 2015. Toward a theory of persuasive hope: effects of cognitive appraisals, hope appeals, and hope in the context of climate change. Health Communication 30(6):598-611.

Chapman, D. A., B. Lickel, and E. M. Markowitz. 2017. Reassessing emotion in climate change communication. Nature Climate Change 7(12):850-852.

Chudek, M., and J. Henrich. 2011. Culture-gene coevolution, norm-psychology and the emergence of human prosociality. Trends in Cognitive Sciences 15(5):218-226.

Cinner, J. 2018. How behavioral science can help conservation. Science 362(6417):889-890.

Clark, M. S., and J. K. Monin. 2014. Turning the tables: how we react to others' happiness. Page Positive emotion: Integrating the light sides and the dark sides. Oxford University Press.

Condon, P., C. Wilson-Mendenhall, and L. Feldman Barrett. 2014. The psychological construction of positive emotion as a window into well-being. Positive emotion: Integrating the light sides and the dark sides. Oxford University Press.

Cushman, F. 2013. The role of learning in punishment, prosociality, and human uniqueness. Page Cooperation and Its Evolution. MIT Press.

van Dijk, E., G. A. Van Kleef, W. Steinel, and I. van Beest. 2008. A social functional approach to emotions in bargaining: When communicating anger pays and when it backfires. Journal of Personality and Social Psychology 94(4):600-614.

van Doorn, J., M. Zeelenberg, and S. M. Breugelmans. 2014. Anger and prosocial behavior. Emotion Review 6(3):261-268.

Drouvelis, M., and B. Grosskopf. 2016. The effects of induced emotions on pro-social behaviour. Journal of Public Economics 134:1-8. 
Elster, J. 1998. Alchemies of the mind: rationality and the emotions. Cambridge University Press, Cambridge.

Fehr, E., and U. Fischbacher. 2004. Third-party punishment and social norms. Evolution and Human Behavior 25(2):63-87.

Fessler, D., and K. Haley. 2003. The strategy of affect: emotions in human cooperation. Page Genetic and Cultural Evolution of Cooperation. MIT Press, Cambridge, MA.

Frank, R. H. 1988. Passions within reason: The strategic role of the emotions. Pages xiii, 304. W W Norton \& Co, New York, NY, US.

Fredrickson, B. L. 1998. What good are positive emotions? Review of General Psychology 2(3):300319.

Frijda, N. H. 2004. Emotions and action. Pages 158-173. Feelings and emotions: The Amsterdam symposium. Cambridge University Press, New York, NY, US.

Frijda, N. H. 2007. The laws of emotion. Lawrence Erlbaum Associates, Mahwah, N.J.

Greenaway, K. H., A. Cichocka, R. van Veelen, T. Likki, and N. R. Branscombe. 2016. Feeling Hopeful Inspires Support for Social Change. Political Psychology 37(1):89-107.

Guala, F. 2012. Reciprocity: Weak or strong? What punishment experiments do (and do not) demonstrate. Behavioral and Brain Sciences 35(1):1-15.

Hargie, O. 2010. Skilled interpersonal communication: research, theory and practice, 5 th Edition. Routledge.

Hirshleifer, J. 1987. On emotions as guarantors of threats and promises. Pages 307-326 The latest on the best: Essays on evolution and optimality. The MIT Press, Cambridge, MA, US.

Hobbs, R. J. 2013. Grieving for the past and hoping for the future: balancing polarizing perspectives in conservation and restoration. Restoration Ecology 21(2):145-148.

Horberg, E. J., C. Oveis, and D. Keltner. 2011. Emotions as moral amplifiers: an appraisal tendency approach to the influences of distinct emotions upon moral judgment. Emotion Review 3(3):237-244.

Hornsey, M. J., and K. S. Fielding. 2016. A cautionary note about messages of hope: Focusing on progress in reducing carbon emissions weakens mitigation motivation. Global Environmental Change 39:26-34.

Jordan, J. J., M. Hoffman, P. Bloom, and D. G. Rand. 2016. Third-party punishment as a costly signal of trustworthiness. Nature 530(7591):473-476.

Kidd, L. R., G. E. Garrard, S. A. Bekessy, M. Mills, A. R. Camilleri, F. Fidler, K. S. Fielding, A. Gordon, E. A. Gregg, A. M. Kusmanoff, W. Louis, K. Moon, J. A. Robinson, M. J. Selinske, D. Shanahan, and V. M. Adams. 2019. Messaging matters: a systematic review of the conservation messaging literature. Biological Conservation 236:92-99.

van Kleef, G. A., A. Cheshin, A. H. Fischer, and I. K. Schneider. 2016. Editorial: the social nature of emotions. Frontiers in Psychology 7.

Kurzban, R., P. DeScioli, and E. O'Brien. 2007. Audience effects on moralistic punishment. Evolution and Human Behavior 28(2):75-84.

Lambert, N. M., A. M. Gwinn, R. F. Baumeister, A. Strachman, I. J. Washburn, S. L. Gable, and F. D. Fincham. 2013. A boost of positive affect: The perks of sharing positive experiences. Journal of Social and Personal Relationships 30(1):24-43.

Lazarus, R. S. 1993. From psychological stress to the emotions: a history of changing outlooks. Annual Review of Psychology 44(1):1-22.

Lazarus, R. S. 2001. Relational meaning and discrete emotions. Pages 37-67 Appraisal processes in emotion: Theory, methods, research. Oxford University Press, New York, NY, US.

Lerner, J. S., Y. Li, P. Valdesolo, and K. S. Kassam. 2015. Emotion and decision making. Annual Review of Psychology 66(1):799-823. 
McAfee, D., and S. D. Connell. 2019. Balancing the benefits of optimism and pessimism in conservation: a response to Kidd, Bekessy, and Garrard. Trends in Ecology \& Evolution 34(8):692-693.

Murphy, R., and M. Murphy. 2012. The tragedy of the atmospheric commons: discounting future costs and risks in pursuit of immediate fossil-fuel benefits. Canadian Review of Sociology/Revue canadienne de sociologie 49(3):247-270.

Nabi, R. L., A. Gustafson, and R. Jensen. 2018. Framing climate change: exploring the role of emotion in generating advocacy behavior. Science Communication 40(4):442-468.

Nelissen, R. M. A., and M. Zeelenberg. 2009. Moral emotions as determinants of third-party punishment: Anger, guilt, and the functions of altruistic sanctions. Judgment and Decision Making 4(7):543-553.

Nesse, R. M., and P. C. Ellsworth. 2009. Evolution, emotions, and emotional disorders. - PsycNET. American Psychologist 64(2):129-139.

Nielsen, K. S., T. M. Marteau, J. M. Bauer, R. B. Bradbury, S. Broad, G. Burgess, M. Burgman, H. Byerly, S. Clayton, D. Espelosin, P. J. Ferraro, B. Fisher, E. E. Garnett, J. P. G. Jones, M. Otieno, S. Polasky, T. H. Ricketts, R. Trevelyan, S. van der Linden, D. Veríssimo, and A. Balmford. 2021. Biodiversity conservation as a promising frontier for behavioural science. Nature Human Behaviour 5(5):550-556.

Ohman, A. 1993. Fear and anxiety : Evolutionary, cognitive and clinical perspectives. Hand-book of Emotions:511-536.

Ojala, M. 2012. Hope and climate change: the importance of hope for environmental engagement among young people. Environmental Education Research 18(5):625-642.

O’Neill, S., and S. Nicholson-Cole. 2009. "Fear won't do it": promoting positive engagement with climate change through visual and iconic representations. Science Communication 30(3):355-379.

Panagopoulos, C. 2010. Affect, social pressure and prosocial motivation: field experimental evidence of the mobilizing effects of pride, shame and publicizing voting behavior. Political Behavior 32(3):369-386.

Peters, E., D. Västfjäll, T. Gärling, and P. Slovic. 2006. Affect and decision making: a "hot" topic. Journal of Behavioral Decision Making 19(2):79-85.

Prestin, A. 2013. The pursuit of hopefulness: operationalizing hope in entertainment media narratives. Media Psychology 16(3):318-346.

Robertson, T. E., D. Sznycer, A. W. Delton, J. Tooby, and L. Cosmides. 2018. The true trigger of shame: social devaluation is sufficient, wrongdoing is unnecessary. Evolution and Human Behavior 39(5):566-573.

Schneider, C. R., L. Zaval, E. U. Weber, and E. M. Markowitz. 2017. The influence of anticipated pride and guilt on pro-environmental decision making. PLOS ONE 12(11):e0188781.

Sigmund, K., H. De Silva, A. Traulsen, and C. Hauert. 2010. Social learning promotes institutions for governing the commons. Nature 466(7308):861-863.

Silvia, P. J. 2008. Interest-the curious emotion. Current Directions in Psychological Science 17(1):57-60.

Sjöberg, L., and L. Sjöberg. 2007. Emotions and risk perception.

Smith, N., and A. Leiserowitz. 2014. The role of emotion in global warming policy support and opposition. Risk Analysis 34(5):937-948.

Smith, R. H., J. M. Webster, W. G. Parrott, and H. L. Eyre. 2002. The role of public exposure in moral and nonmoral shame and guilt. Journal of Personality and Social Psychology 83(1):138-159. 
Snyder, C. R., K. L. Rand, and D. R. Sigmon, editors. 2002. Hope theory: a member of the positive psychology family. Page Handbook of Positive Psychology. Oxford University Press, Oxford [England] ; New York.

Steffen, W., K. Richardson, J. Rockström, S. E. Cornell, I. Fetzer, E. M. Bennett, R. Biggs, S. R. Carpenter, W. de Vries, C. A. de Wit, C. Folke, D. Gerten, J. Heinke, G. M. Mace, L. M. Persson, V. Ramanathan, B. Reyers, and S. Sörlin. 2015. Planetary boundaries: guiding human development on a changing planet. Science 347(6223).

Swaisgood, R. R., and J. K. Sheppard. 2010. The Culture of Conservation Biologists: Show Me the Hope! BioScience 60(8):626-630.

Sznycer, D., J. Tooby, L. Cosmides, R. Porat, S. Shalvi, and E. Halperin. 2016. Shame closely tracks the threat of devaluation by others, even across cultures. Proceedings of the National Academy of Sciences 113(10):2625-2630.

Sznycer, D., D. Xygalatas, E. Agey, S. Alami, X.-F. An, K. I. Ananyeva, Q. D. Atkinson, B. R. Broitman, T. J. Conte, C. Flores, S. Fukushima, H. Hitokoto, A. N. Kharitonov, C. N. Onyishi, I. E. Onyishi, P. P. Romero, J. M. Schrock, J. J. Snodgrass, L. S. Sugiyama, K. Takemura, C. Townsend, J.-Y. Zhuang, C. A. Aktipis, L. Cronk, L. Cosmides, and J. Tooby. 2018. Cross-cultural invariances in the architecture of shame. Proceedings of the National Academy of Sciences 115(39):9702-9707.

Tracy, J. L., A. F. Shariff, and J. T. Cheng. 2010. A naturalist's view of pride. Emotion Review.

Weidman, A. C., J. L. Tracy, and A. J. Elliot. 2016. The benefits of following your pride: authentic pride promotes achievement: authentic pride promotes achievement. Journal of Personality 84(5):607-622.

Weinstein, N., M. Rogerson, J. Moreton, A. Balmford, and R. B. Bradbury. 2015. Conserving nature out of fear or knowledge? Using threatening versus connecting messages to generate support for environmental causes. Journal for Nature Conservation 26:49-55.

Westoby, R., and K. E. McNamara. 2019. Fear, grief, hope and action. Nature Climate Change $9(7): 500-501$.

Williams, L. A., and D. DeSteno. 2014. How positive social emotions motivate actions for the future self: building bonds, attaining ambitions, and establishing esteem. Pages 206-224 Positive Emotion: Integrating the Light sides and Dark sides. Oxford University Press, New York, NY, US.

Xie, X.-F., M. Wang, R.-G. Zhang, J. Li, and Q.-Y. Yu. 2011. The role of emotions in risk communication. Risk Analysis 31(3):450-465. 